\title{
Effect of Incorporating Cellulose Nanocrystals from Corncob on the Tensile, Thermal and Barrier Properties of Poly(Vinyl Alcohol) Nanocomposites
}

\author{
Hudson Alves Silvério, Wilson Pires Flauzino Neto, and Daniel Pasquini \\ Instituto de Química, Universidade Federal de Uberlândia, Campus Santa Mônica, Avenida João Naves de Ávila 2121, \\ 38400-902 Uberlândia, MG, Brazil
}

Correspondence should be addressed to Daniel Pasquini; pasquini@iqufu.ufu.br

Received 3 May 2013; Revised 11 July 2013; Accepted 23 July 2013

Academic Editor: Tong Wan

Copyright (C) 2013 Hudson Alves Silvério et al. This is an open access article distributed under the Creative Commons Attribution License, which permits unrestricted use, distribution, and reproduction in any medium, provided the original work is properly cited.

\begin{abstract}
The effect of incorporating cellulose nanocrystals from corncob (CNC) on the tensile, thermal, and barrier properties of poly(vinyl alcohol) (PVA) nanocomposites was evaluated. The CNC were prepared by sulfuric acid hydrolysis at $45^{\circ} \mathrm{C}$ for 60 minutes, using $15 \mathrm{~mL}$ of $\mathrm{H}_{2} \mathrm{SO}_{4}(9.17 \mathrm{M})$ for each gram of fiber. The $\mathrm{CNC}_{60}$ presented a needle-shaped morphology, high crystallinity $(83.7 \%)$, good initial degradation temperature $\left(236^{\circ} \mathrm{C}\right)$, average length $(L)$ of $210.8 \pm 44.2 \mathrm{~nm}$, diameter $(D)$ of $4.15 \pm 1.08 \mathrm{~nm}$, and high aspect ratio $(L / D)$ of $53.4 \pm 15.8$. PVA/CNC nanocomposite films with different filler loading levels $(3,6$, and $9 \%$ by wt) were prepared by casting. The ultimate tensile strength (UTS), thermal stability (TS), light transmittance (Tr) and water vapor permeability $\left(P_{w}\right)$ of the nanocomposites were measured. When compared to neat PVA film, the UTS of the nanocomposites improved significantly, by $140.2 \%, P_{w}$ decreased up to $28.73 \%$, and there were no significant changes in TS. The nanocomposites also showed excellent Tr in the visible region, maintaining substantially equivalent transparency. These improvements in the nanocomposites' properties suggest a close association between filler and matrix, besides indicating that the CNC were well dispersed and adherent to the polymer matrix.
\end{abstract}

\section{Introduction}

The growing interest in environmentally friendly materials has motivated academic and industrial research in the development and use of biopolymers for applications in which synthetic polymers or mineral fillers have been traditionally used. Toward this end, several biopolymers have been modified to attempt to be competitive with petroleum based polymers with respect to performance and cost. One way to improve the properties of biopolymers and greatly enhance their commercial potential is to incorporate nanosized reinforcement into the polymer [1-3].

In this context, the application of cellulose nanocrystals $(\mathrm{CN})$ as a nanosized reinforcement in polymer matrixes has attracted considerable attention in this field, since it offers a unique combination of desirable physical properties and environmental benefits $[4,5]$. CN based nanocomposites generally exhibit significant improvements in thermal, mechanical, and barrier properties compared to the neat polymer or conventional composites [6]. $\mathrm{CN}$ are needleshaped cellulose particles with at least one dimension equal to or less than $100 \mathrm{~nm}$ and have a highly crystalline nature (almost defect-free crystallites) [7].

The main features that drive the development of $\mathrm{CN}$ as polymer reinforcement agents are their large specific surface area (estimated to be several hundreds of $\mathrm{m}^{2} \cdot \mathrm{g}^{-1}$ ), their very high modulus of elasticity (approximately $150 \mathrm{GPa}$ ), their large aspect ratio, and their ability to act as a significant reinforcement at low filler loading levels. Other attractive advantages of $\mathrm{CN}$ are their low density (about $1.566 \mathrm{~g} \cdot \mathrm{cm}^{-3}$ ), nonabrasive nature, nontoxic character, biocompatibility, and biodegradability. Additionally, $\mathrm{CN}$ come from renewable natural sources that are very abundant and therefore low in cost, so it is not necessary to synthesize them, and they allow the production of composite films with excellent visible light transmittance that can be easily modified chemically (their structure has a reactive surface of $-\mathrm{OH}$ side groups 
that facilitate grafting chemical species in order to achieve different surface properties) $[3,5,7,8]$.

$\mathrm{CN}$ have been isolated from different vegetable sources, such as cotton and wood pulp $[9,10]$, the byproducts from the agricultural industry, such as mango seed [11], sugarcane bagasse [12], rice husk [13] and sesame husk [14], and from animal sources, such as tunicates [15].

Whereas agricultural and agroindustrial residues constitute cellulosic sources available cheaply in large quantities, the production of $\mathrm{CN}$ utilizing those underutilized residues as feedstock provides a commercial application and adds value to those wastes. In addition, the reuse of these residues does not jeopardize food supplies, improves the rural economy, and allows a significant reduction both in the volume of waste accumulated in the environment and in the extraction of raw materials.

The corncob is the central part of the ear of maize in which the grains are embedded and is a waste generated after the grains are removed. For every $100 \mathrm{~kg}$ of ears of maize, about $18 \mathrm{~kg}$ are from corncob [16]. Brazil produced about 58 million tons of maize in the 2010/11 crop. Based on these data, it is estimated that 10.4 million tons of corncobs were generated during this period. Corncob is mainly used for producing animal feed and fertilizer. Therefore, corncob is an agroindustrial waste available in huge quantities in Brazil, which deserves to be properly used in other applications [3].

Poly(vinyl alcohol) (PVA) is the largest synthetic watersoluble polymer produced in the world [17]. PVA is biodegradable under aerobic and anaerobic conditions [18]. PVA is widely used in the textile, adhesive, cosmetic, food, drug, paper, and packaging industries. The main functional uses of PVA include filtration, catalysis, membranes, optics, drug release, enzyme mobilization, and tissue engineering, among others [19]. PVA presents remarkable barrier properties against oils and fats, aromas and perfumes, and small molecules (nitrogen, oxygen, etc.). It is one of the few semicrystalline polymers soluble in water and has good interfacial characteristics and mechanical properties, due to being a hydroxylated polymer capable of forming both intra-and intermolecular hydrogen bonds [20-22].

This biopolymer has excellent film-forming properties and causes no toxic effects in the human body for it is biocompatible. Films made of this material are transparent, have good chemical and thermal stability, and good mechanical strength, are biodegradable and do not represent a threat to the environment. However, the highly hydrophilic nature of these films (which renders PVA a poor barrier to water) critically limits wider application of this polymer and PVAbased composites. In addition, its thermal stability, despite being considered good (initial temperature of degradation $\sim 200^{\circ} \mathrm{C}$ ), may be improved [18, 20-28]. Taking into account the limitations of films made of PVA, the effect of $\mathrm{CN}$ as nanosized fillers on the properties of PVA-based nanocomposites is of interest in the development of novel or improved applications for this polymer, for example, in food and biomedical packaging.

In the literature there are several studies that include, the production of nanocomposites materials with nanostructured cellulose dispersed in PVA matrix. It can be highlighted some examples of the studies using as loading, the nanofibers extracted from soybean [29], soybean pods [30], sulphite wood pulp [31], sugar beet [32], kraft pulp [33], microcrystalline cellulose [34], regenerated cellulose fiber and cellulose fiber pure [35]. In other the cellulose nanocrystals extracted from cotton linter [36], kenaf fibers [37], microcrystalline cellulose [38] works were employed as loading and commercial cotton [39].

The objective of the present research was to evaluate the effect of incorporating cellulose nanocrystals from corncob (CNC) on the tensile, thermal, and barrier properties of poly (vinyl alcohol) nanocomposites. In the present paper, the ultimate tensile strength (UTS), water vapor permeability $\left(P_{w}\right)$, light transmittance (Tr), and thermal stability (TS) of several PVA nanocomposites produced were measured at different filler loading levels.

\section{Materials and Methods}

2.1. Materials. The corncobs were kindly supplied by JC Rações e Insumos Siderurgicos Ltda. (Uberlândia, MG, Brazil). The other reagents employed in this study were sulfuric acid (95.0-98.0 wt\%, Vetec, PA), sodium hydroxide (Vetec), potassium hydroxide (Vetec), sodium chlorite $\left(\mathrm{NaClO}_{2}\right.$, technical grade, $80 \%$, Sigma-Aldrich), glacial acetic acid (Synth), cellulose membrane (D9402, Sigma-Aldrich), phosphorus pentoxide $\left(\mathrm{P}_{2} \mathrm{O}_{5}, 98.5 \%\right.$ Sigma-Aldrich), and polyvinyl alcohol (PVA) (MW = 89.000-98.000) powder (Sigma-Aldrich).

2.2. Preparation of Cellulose Nanocrystals. The $\mathrm{CN}$ were isolated from corncob and characterized according to previous literature; the following is a summary of the methodology employed [3].

2.2.1. Purification. The untreated corncob was ground into a fine powder and treated with an aqueous $2 \%(w / w) \mathrm{NaOH}$ solution for $4 \mathrm{~h}$ at $100^{\circ} \mathrm{C}$, then filtered and washed until neutrality with distilled water. Subsequently this material was bleached at $80^{\circ} \mathrm{C}$ for $6 \mathrm{~h}$ with a solution made up of equal parts $(\mathrm{v}: \mathrm{v})$ acetate buffer and aqueous sodium chlorite (1.7 wt\%). The bleached fibers were filtered and washed until neutrality with distilled water. The fiber content throughout these chemical treatments was about $4-6 \%(w / w)$. These treatments were done in order to purify the cellulose by removing other constituents present in the fibers.

2.2.2. Extraction of Cellulose Nanocrystals. The resulting material from the purification process was used to extract $\mathrm{CN}$. This material was ground into a fine powder. The hydrolysis was performed at $45^{\circ} \mathrm{C}$ for 60 minutes under vigorous stirring, using $15 \mathrm{~mL}$ of $\mathrm{H}_{2} \mathrm{SO}_{4}(9.17 \mathrm{M})$ for each gram of fibers. Following hydrolysis, the suspension was diluted 10-fold with cold water and centrifuged for $10 \mathrm{~min}$ at $7500 \mathrm{rpm}$. The precipitate was then dialyzed against water until neutral $\mathrm{pH}$ ( $\sim 4$ days) was reached. After the dialysis process, the material was ultrasonicated for $10 \mathrm{~min}$ and stored in a refrigerator at $4^{\circ} \mathrm{C}$ with a few drops of chloroform. According to previously published work, the CNC with an acid hydrolysis time of 60 minutes were called $\mathrm{CNC}_{60}$. 
2.3. Preparation of CNC/PVA Nanocomposites. Aqueous $1 \%$ $(\mathrm{w} / \mathrm{v})$ PVA solutions were mixed with an aqueous suspension of $\mathrm{CNC}_{60}$ followed by ultrasonic treatment for $5 \mathrm{~min}$ in order to homogenize the distribution of $\mathrm{CNC}_{60}$ in the mixtures. The weight ratios of $\mathrm{CNC}_{60}$ to PVA were controlled at 3:97 (3\%), 6:94 (6\%), and 9:91 (9\%), respectively. PVA/CNC 60 nanocomposite films and neat PVA film (control sample), were fabricated by casting at $35^{\circ} \mathrm{C}$ for $24 \mathrm{~h}$ in an air-circulating oven. The final mass of all the films was $0.5 \mathrm{~g}$. The PVA/CNC 60 composites and the PVA film were stored in vacuum bags before analysis and testing. The thickness of the films produced ranged from 0.0436 to $0.0583 \mathrm{~mm}$.

\subsection{Characterizations and Measurements}

2.4.1. Mechanical Properties of PVA/CNC Nanocomposites. The ultimate tensile strength (UTS) of the nanocomposite films and neat PVA film were measured with the aid of a universal testing machine (MTS-810 material test system). Sample dimensions were $\sim 30 \mu \mathrm{m}$ thick, $\sim 7.00 \mathrm{~mm}$ wide, and $30 \mathrm{~mm}$ in length. They were tested using a crosshead speed of $1 \mathrm{~mm} \cdot \mathrm{min}^{-1}$ with a load cell of $1 \mathrm{KN}$ at $25^{\circ} \mathrm{C}$. The device was previously calibrated and a total of five measurements were made for each sample to ensure reproducibility of the results.

2.4.2. Water Vapor Permeability $\left(P_{w}\right)$. Water vapor permeability was measured by Payne's cup technique using $\mathrm{P}_{2} \mathrm{O}_{5}$ as a drying agent. To perform the analysis, permeation to water vapor was set up in a system according to Morelli and Ruvolo Filho [40], in which one can analyze the ability of each sample to permeate through its loss of mass (which in this case is directly proportional to the loss of water flowing through the film).

The weight change was noted as a function of time until a constant flux of water was obtained. Through flow $(J)$ was determined by the change in mass versus time corrected by the area of the exposed film:

$$
\left(\frac{\Delta m}{\Delta t}\right) \cdot \frac{1}{A}=J
$$

Using Fick's first law, one can thus determine the coefficient of permeability to water vapor $\left(P_{w}\right)$, knowing the pressure gradient of the water vapor $\left(\Delta P_{v}\right)$ and the sample thickness $(L)(2)$. Two replicates of each sample were placed in a controlled environmental chamber at $25.0 \pm 1.0^{\circ} \mathrm{C}$ and $0 \%$ relative humidity:

$$
J=P w \cdot \frac{[\Delta P v(T)]}{L} .
$$

The procedure for determining $P_{w}$ in this work was carried out analogously to the work of Morelli and Ruvolo Filho [40].

2.4.3. Light Transmittance (Tr). Light transmittance by the nanocomposite films and neat PVA film was measured in a Shimadzu UV-vis spectrometer (model UV-250 1PC) at $25^{\circ} \mathrm{C}$ and correlated based on the film thicknesses using the Lambert-Beer's law. The experiments were carried out in the wavelength range of $200-800 \mathrm{~nm}$ with $0.5 \mathrm{~nm}$ spectral bandwidth. Three samples were used to characterize each material.

2.4.4. Thermal Gravimetric Analysis. Thermal stabilities (TS) of the $\mathrm{CNC}_{60}$ and the nanocomposite films were evaluated using a Shimadzu DTG-60H equipment. The analysis conditions were a nitrogen atmosphere with flow rate of $30 \mathrm{~mL} \cdot \mathrm{min}^{-1}$, heating rate of $10^{\circ} \mathrm{C} \cdot \mathrm{min}^{-1}$, temperature range of 25 to $600^{\circ} \mathrm{C}$, sample mass between 5 and $7 \mathrm{mg}$, and aluminum pans.

\section{Results and Discussion}

In our previous work, the $\mathrm{CNC}_{60}$ were characterized according to their crystallinity index, morphology, and thermal stability. As reported, $\mathrm{CNC}_{60}$ presented a needle-shaped nature, high crystallinity (83.7\%), good initial degradation temperature $\left(236^{\circ} \mathrm{C}\right)$, average length $(L)$ of $210.8 \pm 44.2 \mathrm{~nm}$, diameter $(D)$ of $4.15 \pm 1.08 \mathrm{~nm}$, and high aspect ratio $(L / D)$ of $53.4 \pm 15.8$. The AFM image (Figure 1) supports this evidence for the development of $\mathrm{CN}$ on the nanometric scale [3].

3.1. The Ultimate Tensile Strengths (UTS) and Water Vapor Permeability $\left(P_{w}\right)$ of the Nanocomposites. The effect of the loading content on the ultimate tensile strength (UTS) was evaluated using the $\mathrm{CNC}_{60}$ as a model filler in the PVA matrix. The $P_{w}$ of the $\mathrm{PVA} / \mathrm{CNC}_{60}$ nanocomposites and neat PVA film are presented in Figure 2.

The average UTS of the composites increased by 49.5 , $95.6 \%$, and $140.2 \%$ with $3 \%, 6 \%$, and $9 \% \mathrm{CNC}_{60}$ reinforced PVA, respectively. As expected, increasing the loading content produced an increase in the UTS of the nanocomposites.

Cellulose nanocrystals $(\mathrm{CN})$ prepared from different resources, such as Kenaf fibers [37], cellulose microcrystals (CM) [38] and cotton linter [36] or cellulose nanofibers (CNF) prepared from flax, Kraft pulp, hemp, rutabaga [41] and microcrystalline cellulose [34], exhibited different reinforcements in the PVA matrix. The nanocomposites $\mathrm{PVA} / \mathrm{CNC}_{60}$ prepared in this work showed higher tensile strength than PVA nanocomposites loaded with nanocrystals extracted from kenaf fiber (improvement of $46.2 \%$ with the addition of $9 \mathrm{wt} \% \mathrm{CN}$ ) [37]. In addition, the nanocomposites studied here were also more resistant to traction than the nanocomposites reported by Lee et al. [38], which reported $1 \mathrm{wt} \% \mathrm{CN}$ from microcrystalline cellulose resulted in a significant increase in the tensile strength of films made using PVA as polymeric matrix (49.0\% higher than pure PVA film), but when the load of $\mathrm{CN}$ was increased to $3 \%$ and $5 \%$ in the PVA matrix, the tensile strength gradually decreased [38]. In another interesting study, the authors were able to obtain $26 \%$ increase in TS when $12 \%$ wt of CN extracted from cotton linter were inserted into the PVA matrix [36]. The PVA/CNC 60 nanocomposite films with loads of $6 \%$, and $9 \%$ also had tensile strength well above those of PVA nanocomposites loaded with CN extracted from flax, hemp, or kraft pulp $(10.1 \%, 47.8 \%$, and $60.9 \%$ improvement in UTS, respectively, over adding $10 \mathrm{wt} \%$ of CN) [41]. The nanocomposites of this study also showed superior mechanical performance (tensile 


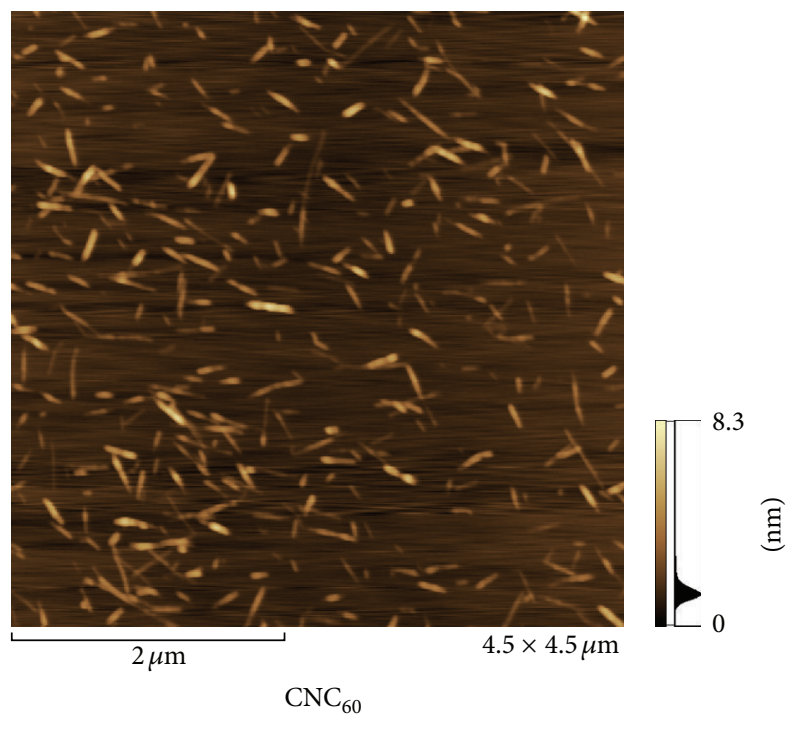

FIGURE 1: AFM image of $\mathrm{CNC}_{60}$.

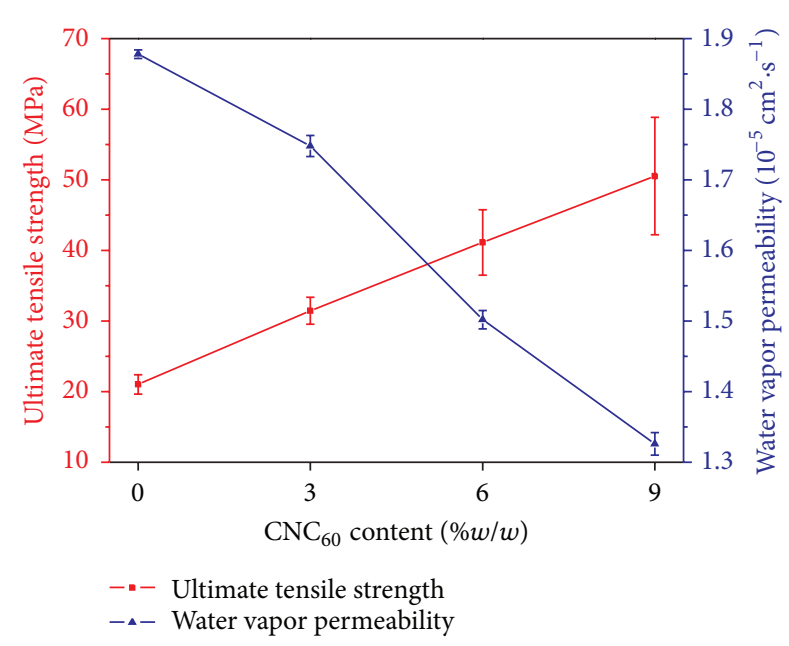

FIGURE 2: Ultimate tensile strength (UTS), and water vapor permeability $\left(P_{w}\right)$ of CNC/PVA nanocomposites and neat PVA film.

strength) than the best result of the work of Frone et al. [34], which obtained $90 \%$ increase in tensile strength with a load of $5 \%$ by weight of $\mathrm{CN}$ from microcrystalline cellulose dispersed in PVA matrix. However, even with 9\% loading, the PVA/ $\mathrm{CNC}_{60}$ film provided a reinforcement less than but comparable to that of a PVA nanocomposite loaded with $\mathrm{CN}$ from rutabaga (158.0\% improvement in UTS with addition of $10 \mathrm{wt} \%$ of CN) [41].

These discrepancies in these results may be attributed to the different PVA employed in the composites preparations, as well as the experimental conditions employed in the preparation of them, which may influence the adhesion between the fillers and the polymer matrix, the uniform distribution of the fillers, the orientation of the fillers, and the degree of crystallinity of the matrix [35]. In addition these results also depend on the characteristics of filler, for example, aspect ratio, modulus of elasticity, specific surface area, type of interactions between themselves, and especially the possibility of forming a percolating network.

The $\mathrm{CNC}_{60}$ reinforced the PVA satisfactorily, given the large increases in UTS presented by the nanocomposites when compared to PVA film. The effect of improving the UTS of films developed in this study may be attributed to the phenomenon of mechanical percolation of cellulose nanocrystals and the formation of a continuous network of cellulose nanoparticles linked by hydrogen interactions, due to good dispersion of nanocrystals in the matrix, which would indicate a good interaction between the components of the nanocomposites.

The use of cellulose nanocrystals extracted from corncobs as a reinforcing agent in nanocomposites is an alternative which can expand the commercial applications of PVA films, for example, in the field of food packaging.

The $P_{w}$ analysis was conducted using the weighing method. Figure 3 graphically represents the change in mass lost $(\Delta m)$ over time $(t)$ in samples of film made of neat PVA or the $\mathrm{PVA} / 3 \% \mathrm{CNC}_{60}, \mathrm{PVA} / 6 \% \mathrm{CNC}_{60}$, and $\mathrm{PVA} / 9 \% \mathrm{CNC}_{60}$ nanocomposites.

In Table 1 values for thickness, area $(A)$, variation in mass lost with time $(\Delta m / \Delta t)$, stream $(J)$ and $P_{w}$ for the films used at a constant temperature $(T)$ of $25.0 \pm 1.0^{\circ} \mathrm{C}$ and a pressure of vaporization $\left(\Delta P_{v}\right)$ of $23.76 \mathrm{mmHg}$ are shown.

The $P_{w}$ values (mean \pm standard deviation) of nanocomposites with different contents of $\mathrm{CNC}_{60}$ are shown graphically in Figure 2.

The growth and metabolism of microorganisms require the presence of water in available form. The most commonly employed measure to express the availability of water in food is water activity (aw). To reduce aw in food, one can increase the concentration of solutes in the aqueous phase of food, either by removing water or by adding solutes; one example is dehydration promoting the removal of water, as with curing or salting and syruping or sugaring, which means adding salt sugar as a solute, thus lowering the aw and preserving the food. A small reduction in aw is often sufficient to have effects in preserving a food; if this reduction is associated with other factors such as the addition of nitrite in some cured meats, or smoking and the use of packaging that does not allow or hinders the entry of water or moisture [42].

Given the necessity of reducing the aw in food packaged in polymeric films, it is very important to evaluate water transport through films produced for this type of application.

In Figure 2, the results obtained with the nanocomposites show a slight reduction in $P_{w}$ compared to the neat PVA film. It can be observed that the water permeability was progressively reduced with increasing content of $\mathrm{CNC}_{60}$; that a phyis, the water permeability of the nanocomposites becomes increasingly poorer with increasing charge on the polymeric matrix. According to Paralikar and his research group, the $\mathrm{CN}$ provide a physical barrier, creating a tortuous path for moisture that permeates the membrane [39]. The nanocomposite films with $3 \%, 6 \%$, and $9 \%$ filler showed increasing improvement in reducing $P_{w}$, by $6.92 \%, 20.02 \%$ and $28.81 \%$, respectively. Even with the increased $\mathrm{CNC}_{60}$ content, the $P_{w}$ continued to reduce; this is at least one 
TABLE 1: Values for thickness, area $(A), \Delta m / \Delta t$, stream $(J)$ and water vapor permeability $\left(P_{w}\right)$ for the films, tested in duplicate.

\begin{tabular}{|c|c|c|c|c|c|c|}
\hline Sample & Thickness (cm) & $A\left(\mathrm{~cm}^{2}\right)$ & $\Delta m / \Delta t(\mathrm{~g} / \mathrm{h})$ & $J\left(\mathrm{~g} / \mathrm{h} \cdot \mathrm{cm}^{2}\right)$ & $P_{w}\left(\mathrm{~cm}^{2} / \mathrm{s}\right)$ & $\begin{array}{c}\text { Average } P_{w}\left(\mathrm{~cm}^{2} / \mathrm{s}\right) \pm \\
\text { standard deviation }\end{array}$ \\
\hline PVA (1) & $5.830 \times 10^{-03}$ & 7.548 & 0.02408 & $3.190 \times 10^{-03}$ & $1.882 \times 10^{-05}$ & \multirow[t]{2}{*}{$1.878 \times 10^{-05} \pm 0.006 \times 10^{-05}$} \\
\hline PVA (2) & $5.799 \times 10^{-03}$ & 7.548 & 0.02410 & $3.193 \times 10^{-03}$ & $1.874 \times 10^{-05}$ & \\
\hline $\mathrm{PVA} / 3 \% \mathrm{CNC}_{60}(1)$ & $5.611 \times 10^{-03}$ & 7.548 & 0.02337 & $3.096 \times 10^{-03}$ & $1.758 \times 10^{-05}$ & \multirow{2}{*}{$1.748 \times 10^{-05} \pm 0.015 \times 10^{-05}$} \\
\hline $\mathrm{PVA} / 3 \% \mathrm{CNC}_{60}(2)$ & $5.534 \times 10^{-03}$ & 7.548 & 0.02341 & $3.101 \times 10^{-03}$ & $1.737 \times 10^{-05}$ & \\
\hline $\mathrm{PVA} / 6 \% \mathrm{CNC}_{60}(1)$ & $4.903 \times 10^{-03}$ & 7.548 & 0.02298 & $3.045 \times 10^{-03}$ & $1.511 \times 10^{-05}$ & \multirow{2}{*}{$1.502 \times 10^{-05} \pm 0.013 \times 10^{-05}$} \\
\hline $\mathrm{PVA} / 6 \% \mathrm{CNC}_{60}(2)$ & $4.842 \times 10^{-03}$ & 7.548 & 0.02301 & $3.048 \times 10^{-03}$ & $1.493 \times 10^{-05}$ & \\
\hline PVA/9\% $\mathrm{CNC}_{60}(1)$ & $4.402 \times 10^{-03}$ & 7.548 & 0.02284 & $3.026 \times 10^{-03}$ & $1.348 \times 10^{-05}$ & \multirow{2}{*}{$1.337 \times 10^{-05} \pm 0.016 \times 10^{-05}$} \\
\hline $\mathrm{PVA} / 9 \% \mathrm{CNC}_{60}(2)$ & $4.360 \times 10^{-03}$ & 7.548 & 0.02269 & $3.006 \times 10^{-03}$ & $1.326 \times 10^{-05}$ & \\
\hline
\end{tabular}

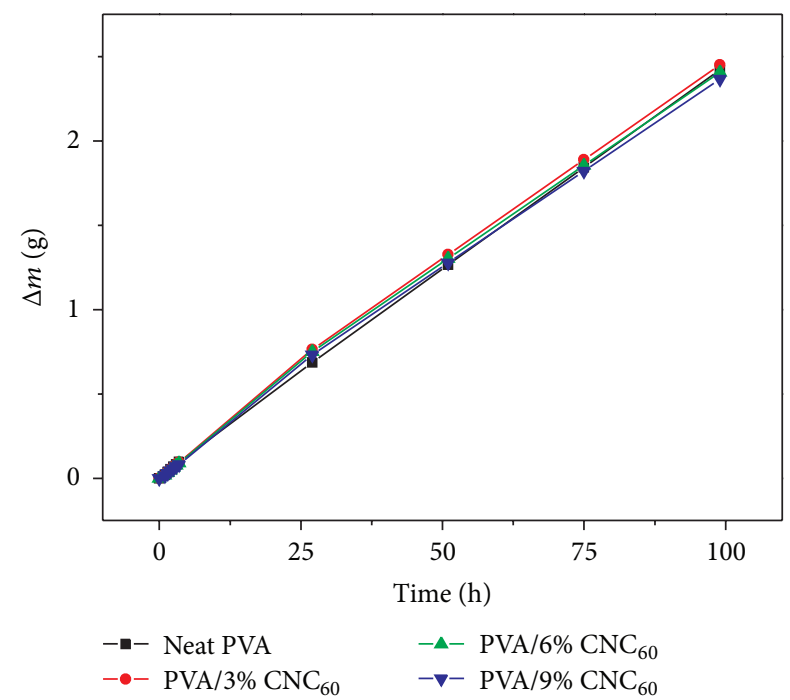

FIGURE 3: $\Delta m$ graphical representation versus time for the neat PVA film and $\mathrm{PVA} / \mathrm{CNC}_{60}$ nanocomposites with $3 \%, 6 \%$, and $9 \%$ filler.

indication that the $\mathrm{CNC}_{60}$ were well dispersed and adherent in the polymeric PVA matrix [43].

The reduction of $P_{w}$ in the films of nanocomposite $\mathrm{PVA} / \mathrm{CNC}_{60}$ can be explained by the physical barrier provided by $\mathrm{CNC}_{60}$ for the passage of water; that is, water must walk along the surface of $\mathrm{CN}$, failing to pass therethrough. This is due to the high crystallinity and the strong interactions between the hydroxyls of cellulose chains of nanocrystals.

Garcia-S and colleagues produced biocomposite films from Carrageenan (a biopolymer extracted from red seaweed, M. stellatus) loaded with levels of $1 \%, 3 \%$, and $5 \%$ by mass of $\mathrm{CN}$ extracted from highly purified $\alpha$-cellulose microfibers (CNW) supplied by the company CreaFill Fibers Corp. (USA), which exhibited reductions in water permeability of $68 \%, 71 \%$, and $58 \%$, respectively, in comparison with the neat Carrageenan film. In summary, the best water barrier performance was found for the film with $3 \% \mathrm{CNW}$ by mass. The author suggested that the highest concentration of CNW led to agglomerations of nanoparticles that no longer dispersed uniformly in the matrix, which was detrimental in terms of improving the barrier [43].

Paralikar and his collaborators have produced PVA membranes (Sigma-Aldrich Inc (St. Louis MO, USA)) loaded with
$10 \%, 15 \%$, and $20 \%$ by weight $\mathrm{CN}$ extracted from commercial cotton (CNXLs) supplied by the Whatman Company (Clifton, NJ, USA), which reduced water flow by approximately $65 \%, 62 \%$, and $54 \%$, respectively, in comparison with neat PVA membrane. The PVA/CNXLs membranes were thermally treated in a convection oven to optimize their crosslinking density, reducing the number of hydroxyls groups on the nanocomposite, and thus its hydrophilicity. The membranes with $10 \%$ CNXLs had a lower $P_{w}$ than those with 15 to $20 \%$ CNXLs, and this was contradictory to what was expected. However, for the authors, the agglomeration of CNXLs observed at the $20 \%$ level may provide channels or areas wherein the membrane allows a higher $P_{w}$; it is likely that the same phenomenon occurred in the membrane with a $15 \%$ load but at a lower intensity [39].

The $\mathrm{CNC}_{60}$ provided a reduction in $P_{w}$ through the membrane. The use of $\mathrm{CNC}$ as a reinforcing agent is an alternative that can expand the commercial applications of PVA films in the field of food packaging, because it maximizes the use of PVA films in environments that contain some moisture and also hinders the growth of bacteria.

3.2. Transparency and Optical Transmittance (Tr) of Nanocomposite Films. Figure 4 shows the physical aspect of the neat PVA film and of the PVA nanocomposite films produced with $9 \%$ by mass $\mathrm{CNC}_{60}$. As can be noted, macroscopically, the incorporation of $\mathrm{CNC}_{60}$ in PVA did not affect the transparency or homogeneity of the films; however, it could not be determined whether there was a uniform dispersion of the reinforcing material, since no specific technique was performed to determine this.

In contrast, the pattern and the lyrics in the background can clearly be seen through the films, showing that they were sufficiently transparent.

Transparency is a useful criterion for the miscibility of the cellulose nanocrystals and the polymeric matrix [44]. The results of electronic spectroscopy in the ultraviolet-visible (UV-VIS) region (200 to $800 \mathrm{~nm}$ ) of the neat PVA film and $\mathrm{PVA} / \mathrm{CNC}_{60}$ nanocomposites with $3 \%, 6 \%$, and $9 \%$ filler mass are shown in Figure 5. The thickness of the films produced ranged from 0.045 to $0.050 \mathrm{~mm}$.

As can be seen in Figure 5, all films exhibited optical transmittances $(\mathrm{Tr})$ very close and excellent in the spectrum of visible light $(390-750 \mathrm{~nm})$ even when the content of $\mathrm{CNC}_{60}$ 


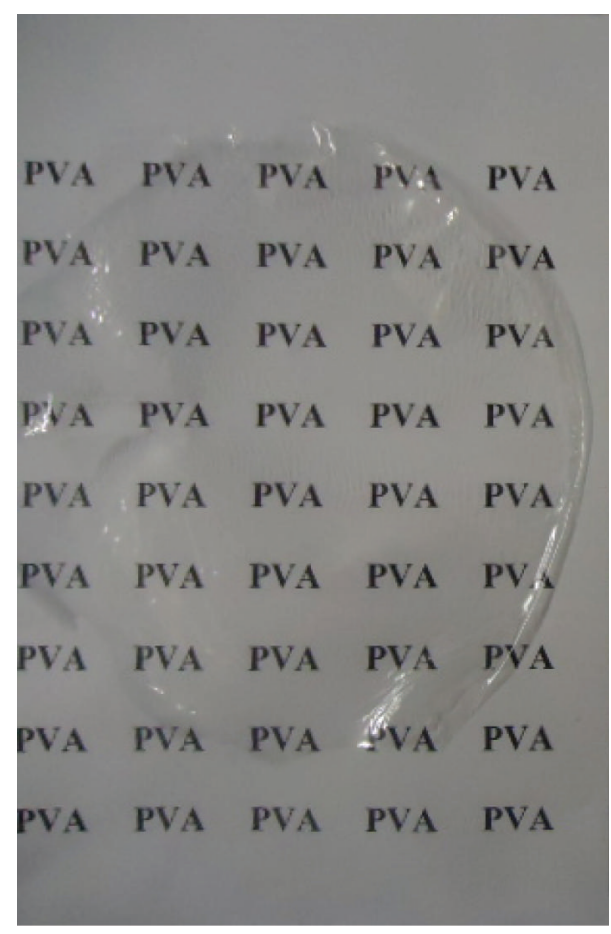

(a)

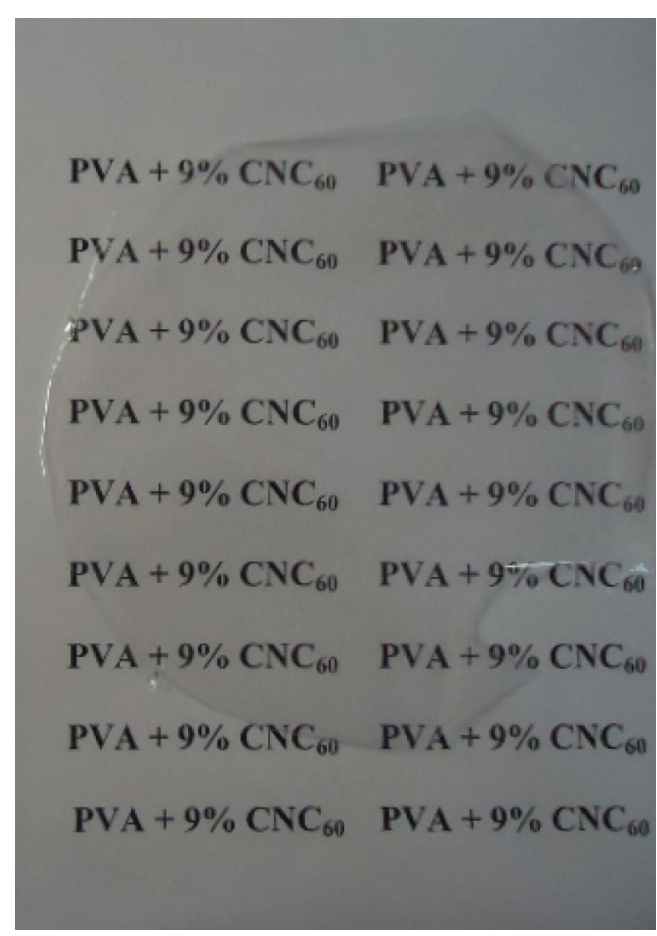

(b)

FIgURE 4: Photos of the films produced. (a) Neat PVA film; (b) nanocomposite film of PVA with 9\% (by weight) $\mathrm{CNC}_{60}$.

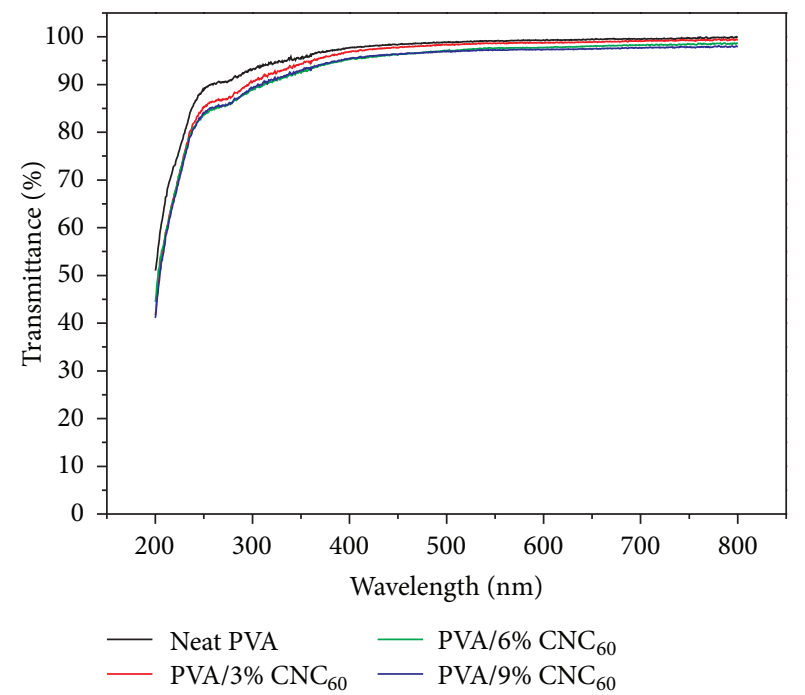

FIGURE 5: Optical transmittance (Tr) versus wavelength (200$800 \mathrm{~nm}$ ) of PVA/CNC ${ }_{60}$ nanocomposite films with $3 \%, 6 \%$, and $9 \%$ filler.

was increased, indicating good miscibility and compatibility of the nanocomposites $[8,45]$. It is known that beyond the refractive index, inherent to each material, the porosity of the film surface also causes light scattering; the excellent $\mathrm{Tr}$ of the films is at least one indication that they were minimally porous $[8,45]$.

The nanometric characteristics of $\mathrm{CNC}_{60}$, with their ultrathin diameter $(4.15 \mathrm{~nm})$ and average length of $210.8 \mathrm{~nm}$, combined with a surface area of high hydrophilicity, substantially improved the intermolecular interactions through hydrogen bonding at interfaces of the $\mathrm{CNC}_{60}$, and PVA matrix; thus, there may have been good dispersal and compatibility of the nanoparticles in the polymeric matrix that, consequently, this implies, resulted in the great transparency of the nanocomposites $[8,45]$.

Nanocomposite PVA/CNC ${ }_{60}$ had Tr values in the visible region greater than those shown by other nanocomposites, such as nanocrystals of microcrystalline cellulose (NCCMC) embedded in a matrix of poly(methyl methacrylate) (PMMA) with $2 \%$ load mass, which showed a Tr around $60 \%$ at $600 \mathrm{~nm}$ [46]; the Tr values of the PVA/CNC 60 films were also higher than those of nanocomposites with $8.4 \% \mathrm{CN}$ from carpet dispersed in PVA, which presented Tr values less than $90 \%$ at $600 \mathrm{~nm}$ [45]; they were also superior to nanocomposites of cellulose acetate butyrate with 10\% NCCMC, which displayed $\operatorname{Tr}$ values of around 50 and $65 \%$ at wavelengths of 600 and $800 \mathrm{~nm}$, respectively [47]. The $\operatorname{Tr}$ values of the nanocomposites of this study at $800 \mathrm{~nm}$ were not higher, but comparable to those of nanocomposites with 10\% NCCMC embedded in a matrix of microcrystalline regenerated cellulose, which showed $\operatorname{Tr}$ of $99.89 \%$ at the same wavelength [44].

\subsection{Thermogravimetric Analysis (TGA) of Nanocomposites.} Thermogravimetric analyses were made for the neat PVA film and the PVA nanocomposite films produced with $9 \%$ by mass $\mathrm{CNC}_{60}$. The thermograms obtained are shown in Figure 6. TG curves of all the films reveal three regions of mass loss. The first region of mass loss is in the temperature range $30-150^{\circ} \mathrm{C}$. 


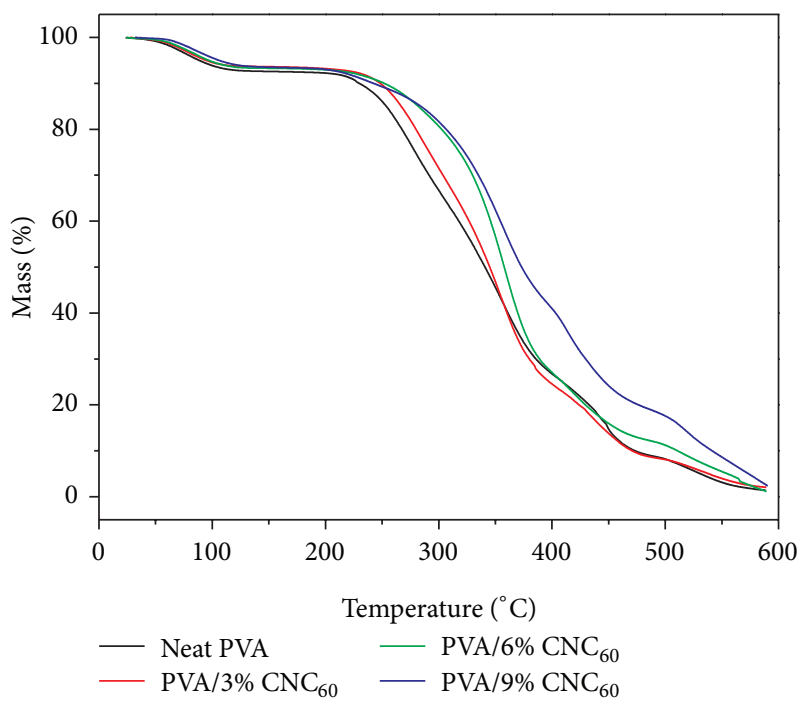

Figure 6: TG curves for films of neat PVA, PVA/3\% $\mathrm{CNC}_{60}$, $\mathrm{PVA} / 6 \% \mathrm{CNC}_{60}$ and $\mathrm{PVA} / 9 \% \mathrm{CNC}_{60}$.

This small loss is due to evaporation of adsorbed water (about $7 \%$ ). The second step at about $220-390^{\circ} \mathrm{C}$ is due to structural degradation of the PVA, with a total mass loss of about $65 \%$. The third stage of weight loss occurred at about $400^{\circ} \mathrm{C}$, possibly due to cleavage of the PVA skeleton or decomposing carbonaceous matter, where the weight loss was above $73 \%$ and gradually increased to approximately $98 \%$ at $590^{\circ} \mathrm{C}$ [38]. The carbonized residues from the films were 1 to $2 \%$ by weight.

Knowing that in general the decomposition of PVA starts around $200^{\circ} \mathrm{C}$ and the thermoplastic processing temperatures also revolve around $200^{\circ} \mathrm{C}$ and sometimes even exceed this value, it is very important that the $\mathrm{CN}$ added to the PVA matrix do not adversely affect the thermal stability of the same order not to hinder the processing of the nanocomposites in an industrial process for example, [26, 27, 48].

The initial temperatures of degradation of pure PVA film and nanocomposites produced stood at about $225^{\circ} \mathrm{C}$. Taking into account the initial temperature degradation, the addition of $\mathrm{CNC}_{60}$ in PVA does not improve the TS of the polymeric matrix; however the TS of nanocomposites has not changed significantly relative to the TS of PVA. In a similar work, but using cellulose nanofibers obtained from microcrystalline cellulose, a slight increase in the initial temperatures of degradation was obtained for PVA nanocomposites, in comparison to the neat PVA, showing an increase of the TS caused by the addition of the filler [34].

The results of thermal stability (TS) obtained in this work are very important because that way any adjustment or modification of the processing of nanocomposites produced by further processing of PVA is not necessary. Thus the $\mathrm{CNC}_{60}$ constitute an interesting model of filler to load PVA without changing their TS.

\section{Conclusions}

The $\mathrm{CNC}_{60}$ provided a significant improvement in the TS of the nanocomposites of $140.2 \%$ when only $9 \%$ of filler had been incorporated.
The reducing the water permeability $\left(P_{w}\right)$ of up to $28.73 \%$ when loading $9 \%$ was used, in the films produced is at least an indication that the $\mathrm{CNC}_{60}$ were well dispersed and adherent on the polymeric PVA matrix. The reduction in permeability to water flow through nanocomposite films provided by corncob cellulose nanocrystals is a very important factor, because these nanofillers reinforce the PVA films and enhance their use in environments containing some moisture while still reducing water activity, which prevents or at least hampers the growth of bacteria. These factors make such films reasonable alternatives that can expand the applications of commercial PVA films in the field of food packaging.

The effect of improving the mechanical and barrier properties of films developed in this study suggest that the formation of a $\mathrm{CN}$ network occurs when the processing allows the formation of strong hydrogen bonds between the cellulose nanoparticles.

The nanocomposites produced were quite transparent, exhibiting optical transmittance $(\mathrm{Tr})(400-800 \mathrm{~nm})$ comparable to the pure PVA film.

The addition of $\mathrm{CNC}_{60}$ in the polymeric matrix of PVA kept the thermal stability of the nanocomposites virtually unchanged in relation to the thermal stability of PVA.

It can be concluded from these results that the $\mathrm{CN}$ obtained from corncobs have a great potential for use as reinforcing agents for producing nanocomposites. In this work, high-performance bionanocomposites for diverse applications were produced by adding cellulose nanocrystals from corncobs to poly(vinyl alcohol), compared to neat PVA films.

\section{Acknowledgments}

The authors thank CAPES/PROAP, CNPq, and FAPEMIG for financial support.

\section{References}

[1] W. P. Flauzino Neto, H. A. Silvério, J. G. Vieira et al., "Preparation and characterization of nanocomposites of carboxymethyl cellulose reinforced with cellulose nanocrystals," Macromolecular Symposia, vol. 319, pp. 93-98, 2012.

[2] A. K. Mohanty, L. T. Drzal, and M. Misra, "Nano reinforcements of bio-based polymers-The Hope And The Reality," Polymeric Materials Science and Engineering, vol. 88, pp. 60-61, 2003.

[3] H. A. Silvério, W. P. Flauzino Neto, N. O. Dantas, and D. Pasquini, "Extraction and characterization of cellulose nanocrystals from corncob for application as reinforcing agent in nanocomposites," Industrial Crops and Products, vol. 44, pp. 427-436, 2013.

[4] Y. Habibi, L. A. Lucia, and O. J. Rojas, "Cellulose nanocrystals: chemistry, self-assembly, and applications," Chemical Reviews, vol. 110, no. 6, pp. 3479-3500, 2010.

[5] B. L. Peng, N. Dhar, H. L. Liu, and K. C. Tam, "Chemistry and applications of nanocrystalline cellulose and its derivatives: a nanotechnology perspective," Canadian Journal of Chemical Engineering, vol. 89, no. 5, pp. 1191-1206, 2011.

[6] H. M. C. Azeredo, L. H. C. Mattoso, D. Wood, T. G. Williams, R. J. Avena-Bustillos, and T. H. McHugh, "Nanocomposite edible films from mango puree reinforced with cellulose nanofibers," Journal of Food Science, vol. 74, no. 5, pp. N31-N35, 2009. 
[7] W. P. Flauzino Neto, H. A. Silvério, N. O. Dantas, and D. Pasquini, "Extraction and characterization of cellulose nanocrystals from agro-industrial residue-soy hulls," Industrial Crops and Products, vol. 42, pp. 480-488, 2013.

[8] R. J. Moon, A. Martini, J. Nairn, J. Simonsen, and J. Youngblood, "Cellulose nanomaterials review: structure, properties and nanocomposites," Chemical Society Reviews, vol. 40, no. 7, pp. 3941-3994, 2011.

[9] S. Beck-Candanedo, M. Roman, and D. G. Gray, "Effect of reaction conditions on the properties and behavior of wood cellulose nanocrystal suspensions," Biomacromolecules, vol. 6, no. 2, pp. 1048-1054, 2005.

[10] E. de Morais Teixeira, A. C. Corrêa, A. Manzoli, F. de Lima Leite, C. de Ribeiro Oliveira, and L. H. C. Mattoso, "Cellulose nanofibers from white and naturally colored cotton fibers," Cellulose, vol. 17, no. 3, pp. 595-606, 2010.

[11] M. A. Henrique, H. A. Silvério, W. P. Flauzino Neto, and D. Pasquini, "Valorization of an agro-industrial waste, mango seed, by extraction and characterization of its cellulose nanocrystals," Journal of Environmental Management, vol. 121, pp. 202-209, 2013.

[12] E. D. M. Teixeira, T. J. Bondancia, K. B. R. Teodoro, A. C. Corrêa, J. M. Marconcini, and L. H. C. Mattoso, "Sugarcane bagasse whiskers: extraction and characterizations," Industrial Crops and Products, vol. 33, no. 1, pp. 63-66, 2011.

[13] S. M. L. Rosa, N. Rehman, M. I. G. De Miranda, S. M. B. Nachtigall, and C. I. D. Bica, "Chlorine-free extraction of cellulose from rice husk and whisker isolation," Carbohydrate Polymers, vol. 87, no. 2, pp. 1131-1138, 2012.

[14] B. S. Purkait, D. Ray, S. Sengupta, T. Kar, A. Mohanty, and M. Misra, "Isolation of cellulose nanoparticles from sesame husk," Industrial and Engineering Chemistry Research, vol. 50, no. 2, pp. 871-876, 2011.

[15] O. van der Berg, J. R. Capadona, and C. Weder, "Preparation of homogeneous dispersions of tunicate cellulose whiskers in organic solvents," Biomacromolecules, vol. 8, no. 4, pp. 13531357, 2007.

[16] R. B. Ziglio, J. R. M. V. Bezerra, I. G. Branco, R. Bastos, and M. Rigo, "Elaboração de pães com adição de farinha de sabugo de milho," Revista Ciências Exatas E Naturais, vol. 9, pp. 115-128, 2007.

[17] B. Ramaraj, "Crosslinked poly(vinyl alcohol) and starch composite films. II. Physicomechanical, thermal properties and swelling studies," Journal of Applied Polymer Science, vol. 103, no. 2, pp. 909-916, 2007.

[18] S. Matsumura, N. Tomizawa, A. Toki, K. Nishikawa, and K. Toshima, "Novel Poly(vinyl alcohol)_degrading enzime and the degradation mechanism," Macromolecules, vol. 32, pp. 77537761, 1999.

[19] M. S. Peresin, Y. Habibi, A. Vesterinen, O. J. Rojas, J. J. Pawlak, and J. V. Seppälä, "Effect of moisture on electrospun nanofiber composites of poly(vinyl alcohol) and cellulose nanocrystals," Biomacromolecules, vol. 11, no. 9, pp. 2471-2477, 2010.

[20] B. C. Isenberg and J. Y. Wong, "Building structure into engineered tissues," Materials Today, vol. 9, no. 12, pp. 54-60, 2006.

[21] I. B. Aranha and E. F. Lucas, "Poli (Álcool Vinílico) modificado com cadeias hidrocarbônicas: avaliação do balanço Hidrófilo/ Lipófilo," Polímeros, vol. 11, pp. 174-181, 2001.

[22] T. Okaya, A. Suzuki, and K. Kikuchi, "Importance of grafting in the emulsion polymerization of MMA using PVA as a protective colloid. Effect of initiators," Colloids and Surfaces A, vol. 153, no. 1-3, pp. 123-125, 1999.
[23] C. A. Finch, Poly(Vinyl Alcohol)_Developments, Wiley, New York, NY, USA, 2nd edition, 1992.

[24] C. M. Hassan and N. A. Peppas, "Structure and applications of poly(vinyl alcohol) hydrogels produced by conventional crosslinking or by freezing/thawing methods," Advances in Polymer Science, vol. 153, pp. 37-65, 2000.

[25] M. Kobayashi, Y. Chang, and M. Oka, "A two year in vivo study of polyvinyl alcohol-hydrogel (PVA-H) artificial meniscus," Biomaterials, vol. 26, no. 16, pp. 3243-3248, 2005.

[26] J. W. Gilman, D. L. Vanderhart, and T. Kashiwagi, Thermal Decomposition Chemistry of Poly(Vinyl Alcohol), chapter 11, American Chemical Society, 1995.

[27] K. Robert, K. Tubs, and T. Wu, "Thermal properties of polyvinyl alcohol," in Polyninyl Alcohol-Properties and Applications, C. A. Finch, Ed., pp. 167-181, John Wliley \& Sons, London, UK, 1st edition, 1973.

[28] D. Ragahavan, "Characterization of biodegradable plastics," Polymer Plastics Technology Engineering, vol. 34, pp. 41-63, 1995.

[29] B. Wang and M. Sain, "Dispersion of soybean stock-based nanofiber in a plastic matrix," Polymer International, vol. 56, no. 4, pp. 538-546, 2007.

[30] B. Wang and M. Sain, "Isolation of nanofibers from soybean source and their reinforcing capability on synthetic polymers," Composites Science and Technology, vol. 67, no. 11-12, pp. 25212527, 2007.

[31] T. Zimmermann, E. Pöhler, and T. Geiger, "Cellulose fibrils for polymer reinforcement," Advanced Engineering Materials, vol. 6, no. 9, pp. 754-761, 2004.

[32] J. Leitner, B. Hinterstoisser, M. Wastyn, J. Keckes, and W. Gindl, "Sugar beet cellulose nanofibril-reinforced composites," Cellulose, vol. 14, no. 5, pp. 419-425, 2007.

[33] J. Lu, T. Wang, and L. T. Drzal, "Preparation and properties of microfibrillated cellulose polyvinyl alcohol composite materials," Composites A, vol. 39, no. 5, pp. 738-746, 2008.

[34] A. N. Frone, D. M. Panaitescu, D. D. Spataru, C. Radovici, R. Trusca, and R. Somoghi, "Preparation and characterization of PVA composites with cellulose nanofibers obtained by ultrasonication," BioResources, vol. 6, no. 1, pp. 487-512, 2011.

[35] Q. Cheng, S. Wang, and T. G. Rials, "Poly(vinyl alcohol) nanocomposites reinforced with cellulose fibrils isolated by high intensity ultrasonication," Composites $A$, vol. 40 , no. 2, pp. 218 224, 2009.

[36] M. Roohani, Y. Habibi, N. M. Belgacem, G. Ebrahim, A. N. Karimi, and A. Dufresne, "Cellulose whiskers reinforced polyvinyl alcohol copolymers nanocomposites," European Polymer Journal, vol. 44, no. 8, pp. 2489-2498, 2008.

[37] J. Shi, S. Q. Shi, H. M. Barnes, and C. U. Pittman, "A chemical process for preparing cellulosic fibers hierarchically from kenaf bast fibers," BioResources, vol. 6, no. 1, pp. 879-890, 2011.

[38] S. Lee, D. J. Mohan, I. Kang, G. Doh, S. Lee, and S. O. Han, "Nanocellulose reinforced PVA composite films: effects of acid treatment and filler loading," Fibers and Polymers, vol. 10, no. 1, pp. 77-82, 2009.

[39] S. A. Paralikar, J. Simonsen, and J. Lombardi, "Poly(vinyl alcohol)/cellulose nanocrystal barrier membranes," Journal of Membrane Science, vol. 320, no. 1-2, pp. 248-258, 2008.

[40] F. C. Morelli and A. Ruvolo Filho, "Nanocompósitos de polipropileno e argila organofílica: difração de raio $\mathrm{X}$, espectroscopia de absorção na região do infravermelho e permeação ao vapor d'água," Polímeros, vol. 20, no. 2, pp. 121-125, 2010. 
[41] A. Bhatnagar and M. Sain, "Processing of cellulose nanofiberreinforced composites," Journal of Reinforced Plastics and Composites, vol. 24, no. 12, pp. 1259-1268, 2005.

[42] http://lucitojal.blogspot.com.br/2010/04/atividade-da-aguaem-alimentos.html, 2013.

[43] M. D. Sánchez-García, L. Hilliou, and J. M. Lagarón, "Morphology and water barrier properties of nanobiocomposites of $\kappa / 1$ hybrid carrageenan and cellulose nanowhiskers," Journal of Agricultural and Food Chemistry, vol. 58, no. 24, pp. 12847$12857,2010$.

[44] H. Ma, B. Zhou, H. Li, Y. Li, and S. Ou, "Green composite films composed of nanocrystalline cellulose and a cellulose matrix regenerated from functionalized ionic liquid solution," Carbohydrate Polymers, vol. 84, no. 1, pp. 383-389, 2011.

[45] C. Tang and H. Liu, "Cellulose nanofiber reinforced poly(vinyl alcohol) composite film with high visible light transmittance," Composites A, vol. 39, no. 10, pp. 1638-1643, 2008.

[46] H. Liu, D. Liu, F. Yao, and Q. Wu, "Fabrication and properties of transparent polymethylmethacrylate/cellulose nanocrystals composites," Bioresource Technology, vol. 101, no. 14, pp. 56855692,2010

[47] J. E. Ayuk, A. P. Mathew, and K. Oksman, "The effect of plasticizer and cellulose nanowhisker content on the dispersion and properties of cellulose acetate butyrate nanocomposites," Journal of Applied Polymer Science, vol. 114, no. 5, pp. 2723-2730, 2009.

[48] M. Roman and W. T. Winter, "Effect of sulfate groups from sulfuric acid hydrolysis on the thermal degradation behavior of bacterial cellulose," Biomacromolecules, vol. 5, no. 5, pp. 1671$1677,2004$. 

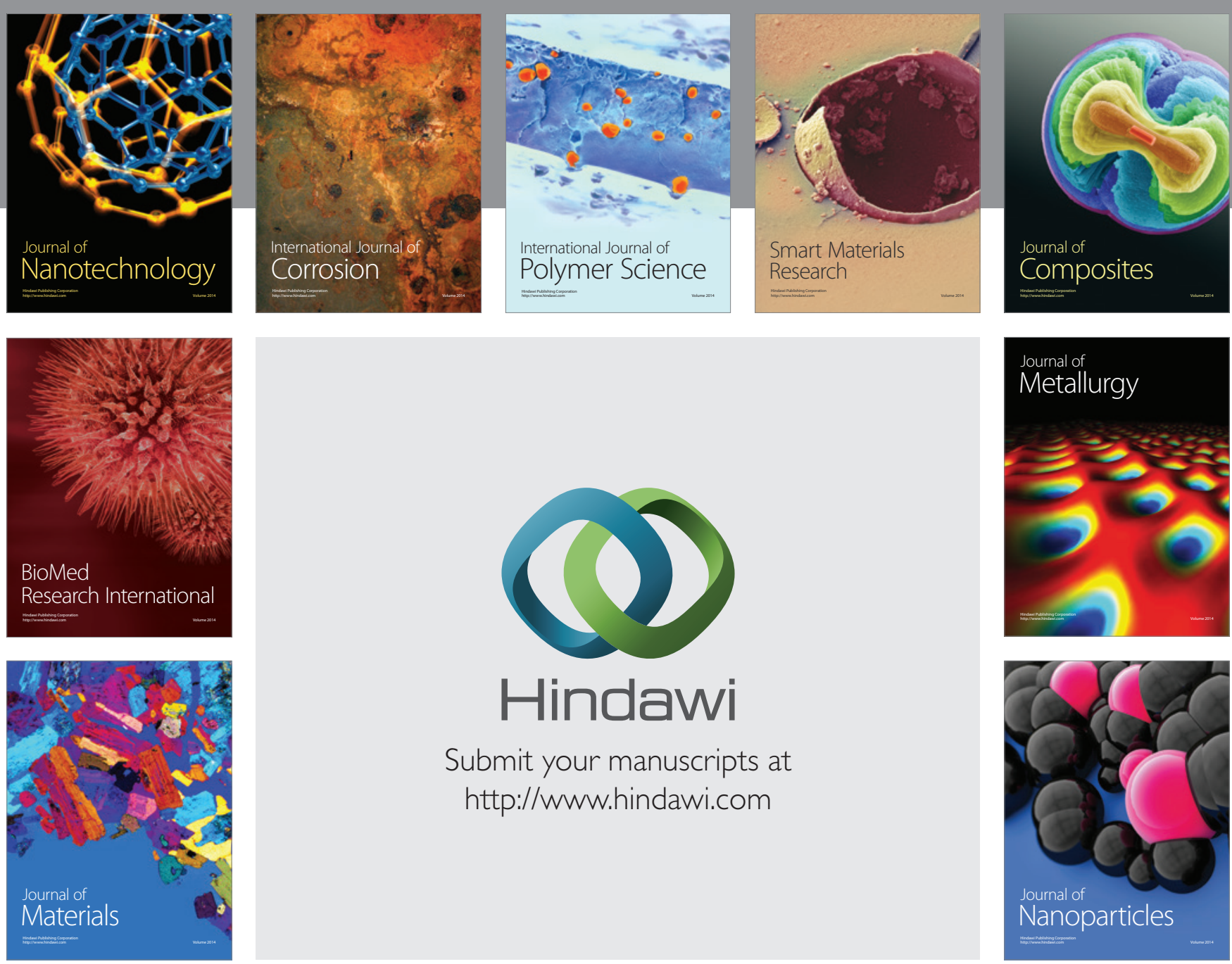

Submit your manuscripts at http://www.hindawi.com
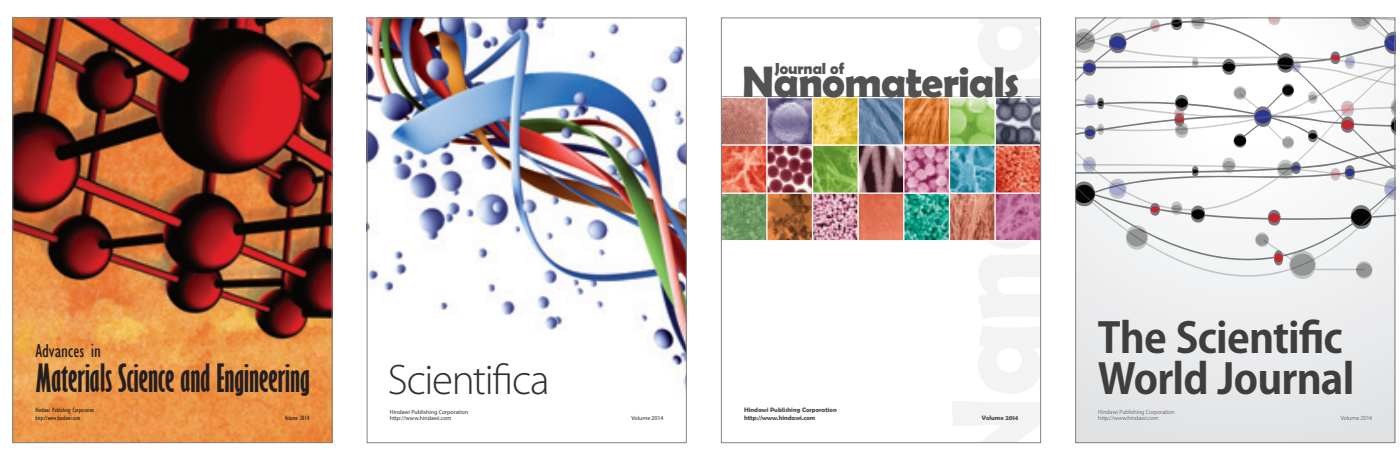

\section{The Scientific World Journal}
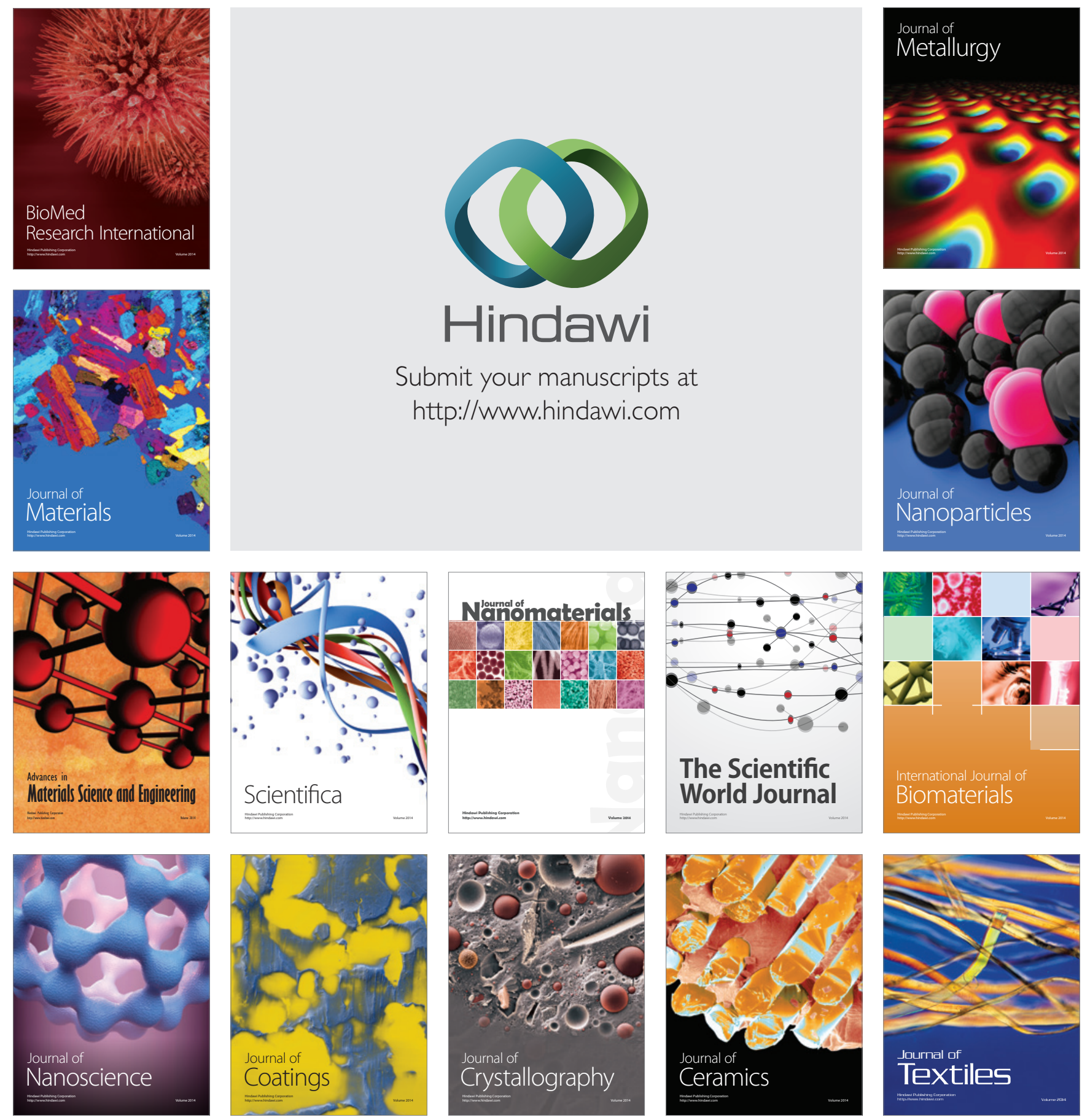